\title{
COMBINING OF NARRATIVE NEWS AND VR GAMES: COMPARISON OF VARIOUS FORMS OF NEWS GAMES
}

\author{
Xiaohan Feng ${ }^{1}$ and Makoto Murakami ${ }^{2}$ \\ ${ }^{1}$ Graduate School of Information Sciences and Arts, \\ Toyo University, Kawagoe, Saitama, Japan \\ ${ }^{2}$ Dept. of Information Sciences and Arts, \\ Toyo University, Kawagoe, Saitama, Japan
}

\begin{abstract}
The information explosion makes it easier to ignore information that requires social attention, and news games can make that information stand out. There is also considerable research that shows that people are more likely to remember narrative content. Virtual environments can also increase the amount of information a person can recall. If these elements are blended together, it may help people remember important information. This research aims to provide directional results for researchers interested in combining $V R$ and narrative, enumerating the advantages and limitations of using text or non-text plot prompts in news games. It also provides hints for the use of virtual environments as learning platforms in news games. The research method is to first derive a theoretical derivation, then create a sample of news games, and then compare the experimental data of the sample to prove the theory. The research compares the survey data of a VR game that presents a story in non-text format (Group VR), a game that presents the story in non-text format (Group NVR), a VR game that presents the story in text (Group VRIT), and a game that presents the story in text (Group NVRIT) will be compared and analyzed. This paper describes the experiment. The results of the experiment show that among the four groups, the means that can make subjects remember the most information is a VR news game with a storyline. And there is a positive correlation between subjects' experience and confidence in recognizing memories, and empathy is positively correlated with the correctness of memories. In addition, the effects of "VR," "experience," and "presenting a story from text or video" on the percentage of correct answers differed depending on the type of question.
\end{abstract}

\section{KEYWORDS}

Virtual reality, multimedia, news games, narratology, interactive.

\section{INTRODUCTION}

Telling stories is an indispensable method of human communication. Stories can express emotions, teach methods, and provide experiences. Therefore, the research of narrative theory is essential for any media production.

Virtual reality, in addition to providing viewers with immersive and novel experiences, is even more interactive than other media. News games, on the other hand, span two areas: news reporting and video games, which are fictional experiences base on real-world sources. Although there are already examples of VR news, such as "Project Syria" and "Hunger in LA" [1], [2]. But VR news games still have a lot of room for development in terms of narrative. 
Signal \& Image Processing: An International Journal (SIPIJ) Vol.12, No.5, October 2021

On the other hand, People are confronted with an unprecedented amount of information. Our response to information has changed in response to our environment. There are four reasons why it has become more difficult for people to get information into their heads.

First, people are sifting through information. In 2011, Americans received five times as much information as in 1986. Excluding working hours, each of us processes 100,000 words every day. Every day, 21,274 television stations around the world provide 85,000 hours of programs, and people watch five hours of video every day. Furthermore, YouTube uploads 6,000 hours of video and computer games per hour, more than all other media combined, including DVD, TV, books, magazines, and the Internet [3]. Especially for Generation Z, who has been online since birth, they no longer have to walk to the library like their parents did; they can just open their phone and type in a keyword and see hundreds of pieces of information. Because of the vast amount of information, people are subconsciously sorting through it every minute and every second.

Secondly, people today tend to let information escape their eyes. Not only directional information, but also letters of all sizes, richly colored pictures, and ubiquitous advertisements on the Internet are constantly taking up space in the brain. Processing all this information makes people tired. People today are becoming accustomed to ignoring large amounts of information in order to maintain a comfortable mood.

In addition to unconscious escapism, mental fatigue causes over-activation of the visual cortex, which lowers the energy in the alpha band of the brain region. Studies have shown that this results in a decrease in executive function. These include executive, sustained, target-guided, cross-attention, and divided attention [4]. Attention and memory are closely related. Since people cannot remember what people have not noticed, people today tend to let information escape their eyes.

Third, because the current media environment is characterized by a large amount of information and easy accessibility, users often see the same type of information. Using news as an example, let me cite three cases. (1) The same news is shown on different platforms within a short period of time. (2) The known news is retweeted on the top page again. (3) Similar incidents recur over a long period of time and new news is made known to the public. With the development of social media, everyone can be a source of information and receive organized information like news from the official media, as well as watch live footages on Twitter in real time. There is so much information that people will lose the right to know it if people start using social media. (4) The exchange of information is fast. It takes only a day or a few hours that incidents become a public topic of conversation after they appear in the social media environment. People's frequent interactions have accelerated the generation, fermentation, and diffusion of public opinion, shortening its cycle. This fast exchange of information causes people to forget old information more quickly.

Thus, it became more difficult for people to get information into their heads. This tends to lead that the information that needs to get public attention is ignored.

As mentioned earlier, the Internet provides a large amount of information and is easily accessible to many people. While the typical Internet user spends about 100 minutes a day on the Internet, students are generally heavy users of the Internet. According to a survey Anderson conducted on students at seven universities in the U.S. and one university in Ireland, Internet-dependent students' Internet usage time (229 minutes / day) is more than three times as much as the other time [5]. Wang and Arrows report that the majority (80\%) of students who responded to their survey spend between 1 and 20 hours a week online. Remaining $20 \%$ of the students spend more than 20 hours a week on the Internet. This group of college students is particularly dependent on 
the Internet [6]. However, spending a lot of time every day on a vast amount of information does not leave much information in their mind, and they expend much energy on it because there is a lot of useless information.

Thus, social problems that cannot be solved without attracting the attention of public opinion are likely to be buried in the vast amount of information and will not leave an impression. Even if they are noticed, the repetition of the same type of information reduces the public's sensitivity to it, and their emotional response to it gradually weakens.

A research by Dan Linz, Ed Donnerstein, and Steve Penrod measured the reactions of male college students to films of violent behavior. These films depicted violence against women and sexual content. After the subjects watched these clips for five days, the researchers compared the data from the first day to the last day. Clearly, after watching the information repeatedly, the subjects' self-reported anxiety levels dropped significantly. Initially, the film was perceived as aggressive and insulting, but by the fifth day, it was rated as "not so serious" and the subjects are no longer depressed while watching it. After the experiment, the subjects watched a video of a rape trial and judged the rape victim's victimization as mild, compared to a group of the general public who had never done the experiment. Further research by the research team found that empathy for rape victims decreased after the experiment [7].

Christopher Pieper, Leonard D. Eron, and L. Rowell Huesmann believe that prolonged exposure to media with violent messages can numb the negative emotional response that children and adults have to violence. And to a certain extent, the physiological response of unpleasant emotions disappears and recipients begin to numb their own and others' feelings of violence. They become less likely to take any action to help the victim of violence. This is the so-called bystander effect [8].

In 1964, the famous rape and murder case of Kitty Genovese took place. According to media reports, 38 bystanders watched for 30 minutes without helping. Social psychologists Bibb latané and John Darley investigated why so many people are not helping the victim. Through a series of experiments, the researchers found that the presence of more bystanders encourages the dispersal of blame and limits an individual's motivation to intervene [9].

In 1968, Darley and latané conducted experiments and research on the dispersion of responsibility in the "bystander effect". The results showed that when there is someone else around, actions to help the victim are delayed, slowed down, and even cancelled out the possibility of helping the victim. The reason for this is that people tend to believe that others will take the blame for them, or that they are not qualified to help [10]. The same phenomenon is occurring in the Internet society. Studies have shown that people reply faster to emails sent to individuals than to group because they feel more responsible for individual emails than for group emails. By not making it clear to whom the email is addressed, responsibility is distributed and the efficiency of replying is reduced [11].

Combine this situation with today's new media news. People can see other people's feedback underneath the news. This indicates a high participation rate in new media. High participation means that any user can participate in social media and use the various features that social media offers. Each user can engage extensively with content in social media, creating content, modifying information, and sharing and commenting on information. There is a clear sense that online media is more for the masses than traditional media. This can easily lead to a feeling of distributed responsibility. On the other hand, if the information is intended for individuals, theoretically, the distribution of responsibility is reduced, making it easier for the recipients to notice and remember the information. 
To summarize the issues.:

- Social problems that can only be solved by attracting the attention of public opinion are likely to be buried in the vast amount of information, and will not leave a lasting impression.

- The current media environment makes it easy to forget details of information.

- When the same type of information is repeatedly presented, the public's sensitivity to that information decreases and their emotional response gradually weakens.

- It is clearly felt that the online media is more suitable for the masses than the traditional media. This is likely to cause a feeling of dispersed responsibility. This is the so-called bystander effect.

According to neurologist Michael Smith, when people watch narrative images that induce empathy, the brain automatically filters out external influencing factors to focus on learning and cognition, indicating that the human mind wants to know the unknown from a narrative perspective. He believes that without a narrative connection, people cannot stay in the brain for long [12]. There is also considerable research showing that memories of events with a strong narrative component are more likely to be remembered [13]. And many studies have revealed that an immersive virtual reality system can better facilitate situational memory performance [14], [15].

Consequently, research reinforce memory through narrative and immersion, and bring players into an independent worldview in the form of VR games to increase the target ability of information transfer and reduce the psychology of distributed responsibility. To address these issues, this research proposes that using virtual reality technology to gamify narrative news is a way to make news more deeply memorable. At the same time, new questions arise, what kind of narrative techniques would be suitable for news games, and could VR affect the outcome?

Therefore, the main purpose of this research is to explore the above questions. Samples will be created from the perspective of narrative theory, and research will examine which sample's story information is most deeply embedded in the subject's mind.

This research aims to provide directional results for researchers interested in combining VR and narrative, enumerating the advantages and limitations of using text or non-text plot prompts in news games. It also provides hints for the use of virtual environments as learning platforms in news games.

\section{MeTHODS}

The research method is to first derive a theoretical derivation, then create a sample of news games, and then compare the experimental data of the sample to prove the theory.

Research compared the survey data of a VR game that presents a story in non-text format (Group VR), a game that presents the story in non-text format (Group NVR), a VR game that presents the story in text (Group VRIT), and a game that presents the story in text (Group NVRIT) will be compared and analyzed.

This paper describes the experiment. Specifically, university students will be surveyed, and 30 students in each group will experience the sample. After the experience, they will be asked to fill out a questionnaire and data will be collected. Finally, the collected data will be analyzed and conclusions will be drawn by comparing them with the expected results. All subjects were 
Signal \& Image Processing: An International Journal (SIPIJ) Vol.12, No.5, October 2021

recruited through convenience sampling and snowball sampling. The original plan was for some subjects to experience the VR face-to-face with the researchers, but this was all changed to online because of COVID-19 situation. Subjects were asked to download the samples through a link provided by the researcher, experience the samples on their respective devices, and mail answers of a questionnaire. All subjects were aware of and consented to the experiment before it was conducted.

The sample is based on actual events. More than $80 \%$ of the text is taken directly from the news interviews. References are to newspaper articles about the incident from 2006 to 2015. These news stories were distributed across diverse media platforms over a long period of time. They were selected as scenarios for the news game because of their integrative nature and the narrative nature required for this experiment.

The synopsis is that the main character was taken to a remote countryside by human traffickers and forced to marry her "husband". The protagonist tried to commit suicide many times without success. She was recruited by the local school as a temporary teacher, and the children and students gave her new hope. A photographer discovered and photographed this, and the incident became known to the public. However, the local government and residents became frustrated with these reports and would not allow the reporter to cover the story, claiming that it exposed human trafficking and the poverty of education, and the school expelled the protagonist. When these facts were uncovered, social discontent rose again, and the local government, under pressure from public opinion, reinstated the protagonist as a teacher.

The sample is divided into four stages, each with one or two enemies and two key items, and the player needs to collect the key items while avoiding enemy pursuit. The enemies are designed to symbolize hostility and the protagonist's fears, such as "husbands," "fear of forced childbirth," and "local government. The key items in each stage are related to the storyline of that stage. In the case of the Group VRIT and Group NVRIT samples, picking up a key item automatically displays text describing the story in the first person of the protagonist, in the case of the Group VR and Group NVR samples, picking up a key item plays a video that is projected full screen, the video is produced in 3ds Max, and the text used in the narration and the text group is the same. Once the items are aligned, the player can move on to the next stage.

The samples in non-VR group are displayed on a traditional screen of PC with a maximum resolution of 1920x1080; VR group use VR headsets and controllers for PC. The subjects in the VR group have full control over navigation and manipulation of objects (key items). Videos for the non-text group were produced using 3ds Max, and the characters are real scale 3D character modeling silhouettes. The same video was used to ensure consistency in the non-text group, given the possible influence of the lens language. The background color of this video is black, and the surroundings are also black when viewed on a VR device, thus creating a fake 360-degree video effect. Since the characters do not come behind the player, the experience is more like watching a play; the difference between the VR group and the NVR group is that the play is viewed on a computer screen and the actors perform the play in front of the subject. In addition to this, the non-text group contains more modality sensory information, such as narration and background music, than the text group.

\subsection{Sample}

First, decide on the mood of the game and draw a sketch of the scene. Since this news game had a horror-like atmosphere, researchers chose an appropriate one from the sketches. Design the game characters and draw the front and side views of the characters for modeling. After completing the design of the game's characters and scenes as shown in Figure 1, modeling is done in 3ds Max. 
Signal \& Image Processing: An International Journal (SIPIJ) Vol.12, No.5, October 2021

Before modeling, import the front and side views into the background to build the character model more accurately. Once the modeling is complete, create the texture.

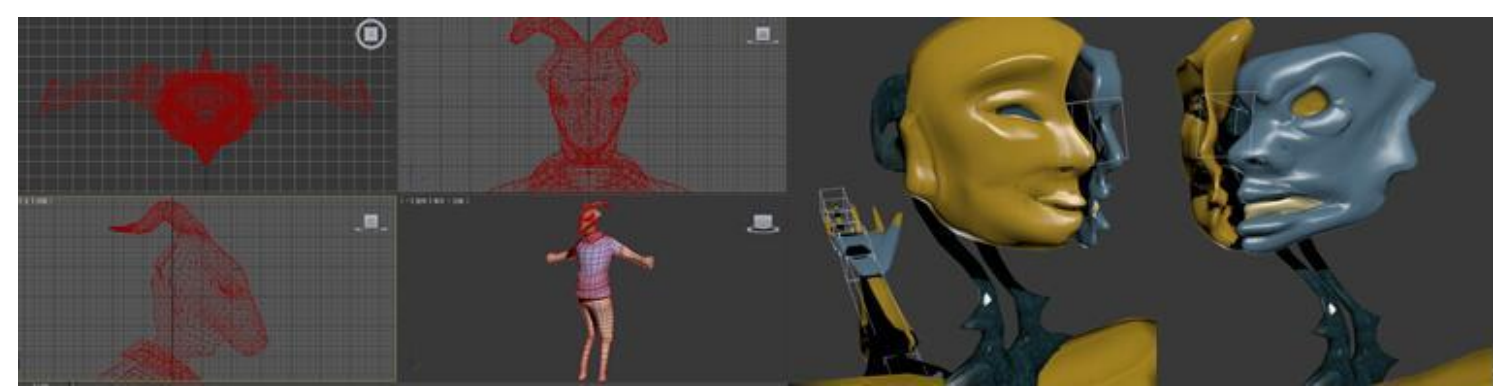

Figure 1. Modeling with 3ds Max

As shown in Figure 2, in order to make the texture position correspond to the model position, the model is introduced into UNFOLD3D and the texture is expanded. This step is very important, as it not only facilitates the texture drawing step, but also reduces the probability of wrong texture positions when the model is subsequently introduced into the game production engine. Although stickers can actually be deployed in 3ds Max, researchers chose to use stickers in this production because the functions of UNFOLD3D are more intuitive and easy to operate.

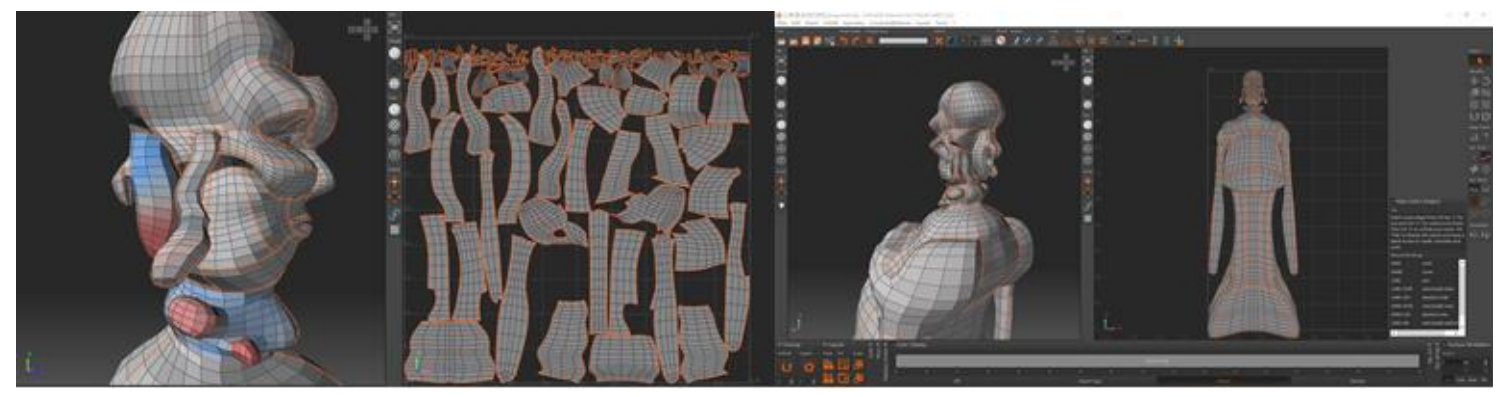

Figure 2. Unfold the texture with Unfold 3d

The next step is to import the model into Mudbox and draw the texture, which can be done in ZBrush, but since It doesn't need to change the model form for this step, researchers chose a smaller software. It is also important to note that if a model that already has a texture developed changes its morphology, the texture will be wrong.

Back in 3ds Max again, bound the bones, moved the bones in the model, and used keyframe animation to animate the character walking, running, and attacking.

Finally, import the characters and scenes into Unity to create the game. The game screen is shown in Figure 3.

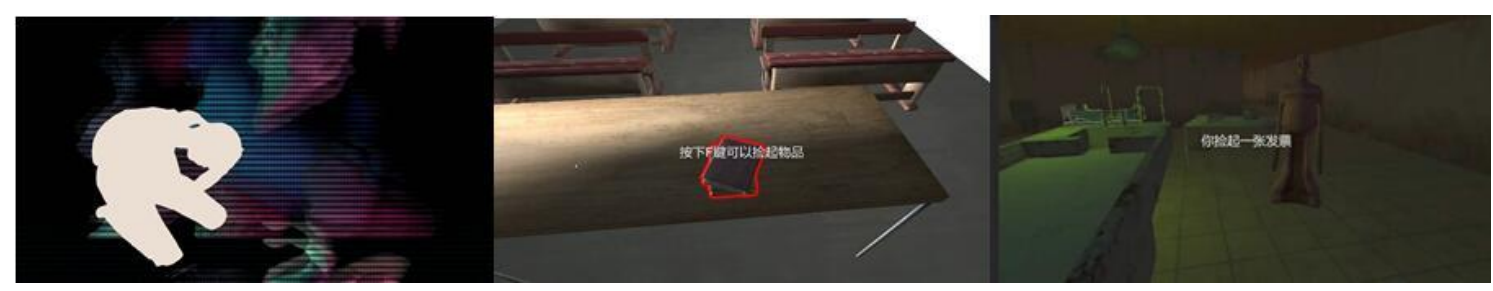

Figure 3. The sample screen 
Signal \& Image Processing: An International Journal (SIPIJ) Vol.12, No.5, October 2021

\subsection{Questionnaire}

The questionnaire is divided into four written questionnaires and one recorded questionnaire the written questionnaire consists of basic information, recognition check, correctness check, and empathy check, as shown in Table 1. While the recorded questionnaire consists of subjects telling a story and giving their impressions of the sample. The basic information questionnaire asks the subjects their age, gender, major, gaming experience, experience using VR, and the theme of the sample.

The recognition check and the correctness check use the same 10 questions. The purpose of the recognition check is to find out how much the subjects themselves think they know about the sample story, and their actual cognitive status is not important in this check. In the empathy check, the strength of the empathic emotion for each subject is investigated through a self-report questionnaire.

Table 1. Questionnaire.

\begin{tabular}{|l|l|l|l|}
\hline Basic information & \multicolumn{3}{|l|}{ Gender } \\
\hline Age & No & Yes \\
\hline Have you ever used VR? & No & Yes \\
\hline $\begin{array}{l}\text { Have you paid attention to the news } \\
\text { of female population sales? }\end{array}$ & $\begin{array}{l}\text { Have you read related articles on this } \\
\text { game? }\end{array}$ & No & Yes \\
\hline
\end{tabular}

\begin{tabular}{|l|l|l|l|l|l|}
\hline Recognition check & Get it & $\begin{array}{l}\text { Maybe } \\
\text { Get it }\end{array}$ & $\begin{array}{l}\text { Not } \\
\text { sure }\end{array}$ & $\begin{array}{l}\text { Maybe } \\
\text { don't } \\
\text { get it }\end{array}$ & $\begin{array}{l}\text { Don't } \\
\text { get it }\end{array}$ \\
\hline $\begin{array}{l}\text { Where the protagonist was } \\
\text { kidnapped? }\end{array}$ & & & & & \\
\hline Who bought the protagonist? & & & & & \\
\hline $\begin{array}{l}\text { What is the attitude of the protagonist } \\
\text { s husband towards her? }\end{array}$ & & & & & \\
\hline $\begin{array}{l}\text { What are the protagonists' means of } \\
\text { suicide? }\end{array}$ & & & & & \\
\hline Why the protagonists left the village? & & & & & \\
\hline $\begin{array}{l}\text { What reminds the protagonist of life's } \\
\text { hopes? }\end{array}$ & & & & & \\
\hline $\begin{array}{l}\text { How is the protagonist known to the } \\
\text { public? }\end{array}$ & & & & & \\
\hline $\begin{array}{l}\text { Why doesn't the local government } \\
\text { want the public to know about the } \\
\text { protagonist? }\end{array}$ & & & & & \\
\hline $\begin{array}{l}\text { What is the attitude of the villagers } \\
\text { towards this? }\end{array}$ & & & & & \\
\hline Did you understand the ending? & & & & & \\
\hline Correctness check & & & & \\
\hline Full score 100 Correct answer $+\mathbf{1 0}$ & & & & \\
\hline
\end{tabular}


Signal \& Image Processing: An International Journal (SIPIJ) Vol.12, No.5, October 2021

\begin{tabular}{|c|c|}
\hline \multicolumn{2}{|c|}{ Empathy check } \\
\hline Stage & No feeling $\longrightarrow$ \\
\hline \multicolumn{2}{|r|}{ (r) } \\
\hline \multicolumn{2}{|l|}{2} \\
\hline \multicolumn{2}{|l|}{3} \\
\hline \multicolumn{2}{|l|}{4} \\
\hline \multicolumn{2}{|c|}{ : No feeling } \\
\hline \multicolumn{2}{|c|}{ : Feeling emotions, but not enough to take action. } \\
\hline \multicolumn{2}{|c|}{ : Feels emotional and takes short-term/single/simple actions. } \\
\hline \multicolumn{2}{|c|}{$\begin{array}{l}\text { : Feels emotional and takes long-term/ continuous/ } \\
\text { /complex actions. }\end{array}$} \\
\hline
\end{tabular}

\section{EXPERIMENTAL RESUlTS AND ANALYSIS}

\subsection{Basic information}

In the research of the experiment, 120 Chinese college students participated, of which, 59 were females and 61 males with a mean age of 20.8 years, age range of $18-24$ years, and $\mathrm{SD}=1.294$. The groups were divided, 19 females and 11 males in the NVR group, age range 19-23 years, mean age 20.733 years, $\mathrm{SD}=1.263 ; 18$ females and 12 males in the NVRIT group, age range 1824 years, mean age $20.733, \mathrm{SD}=1.263 ; 13$ females and 17 males in the VR group ranging from 19 to 23 years old, mean age 20.833, $\mathrm{SD}=1.240$; and, 9 females and 21 males in the VRIT group ranging from 19 to 24 years old, mean age $20.933, \mathrm{SD}=1.314$.

Although the overall ratio of male to female subjects is basically the same, the ratio of male to female subjects in each group is different; the ratio of male to female subjects in the four groups is shown in Figure 4, it can be seen that the NVR and NVRIT groups have a significantly higher percentage of females than the other two groups. In the process of recruiting the subjects, the NVR and NVRIT groups collected 30 subjects quickly. On the other hand, the VR and VRIT groups were two to three days late in recruiting. Even after the NVR and NVRIT groups were full, there were still college students who came to be recruited, but they did not have VR devices and thus could not participate in this experiment. More than half of these applicants were female, and in a 2017 gender survey on VR and AR device ownership [16], 43\% of device owners were female and $31 \%$ of prospective device buyers were female. According to data from another U.S. gamer gender survey, the highest percentage of female gamers was 48\% since 2006 [17]. Combining the data from this survey and its collection process, the number of women who own VR devices is small compared to men, but the number of women who are interested in gaming is not small. 
Signal \& Image Processing: An International Journal (SIPIJ) Vol.12, No.5, October 2021

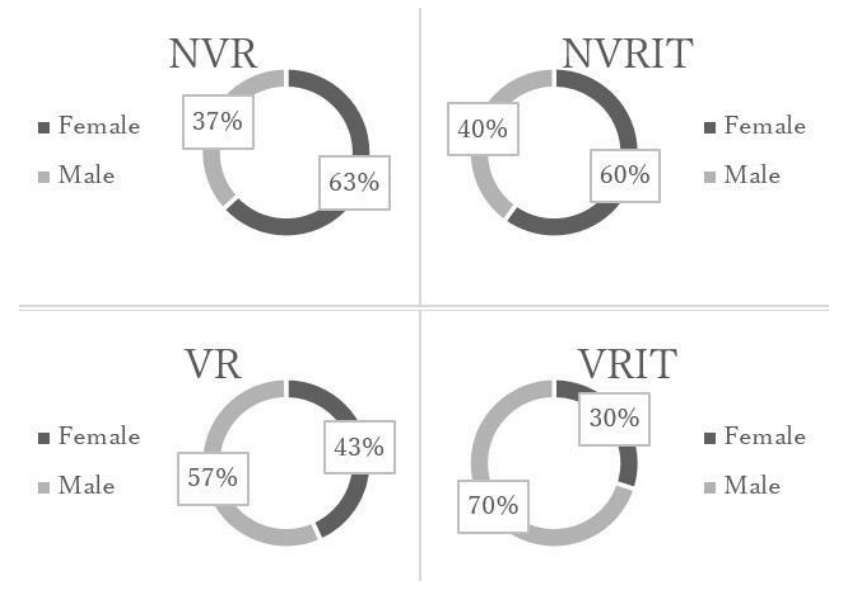

Figure 4. Gender ratio of the four groups

The 120 subjects also included 23 from the Department of Science and Engineering, 18 from the Department of Education, 16 from the Department of Management, 15 from the Department of Arts, 13 from the Department of Architecture, 12 from the Department of Literature, 9 from the Department of Economics, 7 from the Department of Sociology, 3 from the Department of Physical Education, 2 from the Department of History, 1 from the Department of Law, and 1 from the Department of Philosophy. A variety of majors applied. The diversity of subjects' majors is beneficial in getting more diverse perspectives in the recorded survey.

When the subjects self-reported their gaming experience, 87 said they had a lot of gaming experience, 21 said they had normal gaming experience, and 12 said they had little gaming experience. Quite a few of the subjects who considered their gaming experience to be normal and low often watched live game shows, even though they did not play games themselves. On the whole, the subjects have a lot of gaming experience. This also can be seen from the behavior of the subjects. When the sample was given, there was no mention of how to play or operate the game, and as a result, there are no questions asked by the subjects; the subjects sought ways to clear the game from their own game experience. This was one of the reasons why research chose university students as subjects; research deliberately chose targets with a lot of gaming experience and expected more obvious results in terms of recipients filling in the gaps by themselves. In terms of the results, this is the right choice.

\subsection{Recognition check}

Fig. 5 shows the percentage and number of times each option was selected in each group. Overall, the NVRIT group was the most confident in their perception, followed by the NVR group, then the VRIT group, and finally the VR group, with a slight difference from the VRIT group. The NVRIT group is more confident in their self-perception than expected. Compared to the NVR group, which is also a non-VR format sample, the number of times the "Get it" option was selected exceeded 100 times. When compared to the VRIT group, which presents the story in the same text, the NVRIT group selected "Get it" more than twice as many times as the same group. The selection patterns of the other three groups are more similar, with most of the selections distributed between "Get it" and "Maybe get it," a certain number of "Not sure," a small number of "Maybe don't get it," and zero selections of "Don't get it." NVRIT group's choices were concentrated on "Get it", with very few "Maybe get it" and "Not sure" choices compared to the other groups. In the NVRIT group, the number of choices for "Maybe don't get it" is zero, and the number of times "Don't get it" was selected is zero. Among all responses, "Don't get it" was selected only in the NVRIT group. 
Signal \& Image Processing: An International Journal (SIPIJ) Vol.12, No.5, October 2021

\begin{tabular}{|l|l|l|l|l|l|}
\hline Non VR \\
\hline NVR
\end{tabular}

Figure 5. The percentage and number of times each option was selected in each group

Of the three groups with similar selection patterns, the NVR group is more confident in their selfperception. The difference in the number of times they selected "Get it" and "Maybe get it" was the largest among the other three groups. The difference in self-perception between the VRIT group and the VR group is not clear. The difference in self-perception between the VRIT group and the VR group is not clear: the two groups chose the same number of "uncertainties," but the VR group was the only group that chose "Maybe get it" more often than "Get it". The VR group also selected "Maybe don't get it" more often than the VRIT group. This indicates that the selfperceived confidence of the VR group is the lowest among all groups.

Through the experimental records of previous research and additional interviews [18], they found that the average number of years of VR purchase for the VR group was two years, with the highest number of people acquiring VR in 2019. The average time spent using VR was 10 hours per month; they had been using VR devices for longer periods of time, but were more dense when they did use them. In many cases, the same was true for the VRIT group; subjects who said they had not recently played any VR games that particularly interested them had consequently not taken out their VR devices for nearly six months prior to the experiment. Combining the data 
Signal \& Image Processing: An International Journal (SIPIJ) Vol.12, No.5, October 2021

from the two VR and non-VR samples reconfirmed that subjects' self-reported experience with memory was positively correlated. Studies have shown that the more experience you have, the more confident you are in identifying your memories [19]. This is the reason why the NVRIT group was so confident in their self-identification of memories. Even though video media has become more common, text is still the largest medium through which people access information on a daily basis. Regardless of the ability of the visual media to make viewers remember more information, from the perspective of cumulative experience, people always experience more text than video from birth to adulthood.

The research also took into account that the total amount of text in the VRIT and NVRIT samples was small, divided into eight groups, with only 300-500 words in each group. It remains to be seen whether the same results can be obtained with longer texts. Since this experiment was conducted with college students with gaming experience as subjects, the gaming experience and the experience of reading short texts are one of the reasons for the NVRIT group's confidence in self-awareness.

\subsection{Correctness check}

The same question is used for the recognition check and the correctness check. There are five levels of correctness depending on the subject's answer. A high percentage of subjects went beyond the correct answers in certain questions, adding more correct details to their answers. For example, the first question asks where the main character is abducted and sold. The answer is "the train station". Nearly half of the subjects answered not only the train station, but also specific city information. For these answers, the researchers classified them as "more than correct". The answers that matched were considered "correct". Those who gave even slightly wrong answers were placed in the "mostly correct" category and vice versa. Finally, answers that are completely wrong are categorized as "incorrect". Answers that are out of range, but not completely correct, are also classified as "mostly correct.

The score for each level is: "More than correct": 5, "Correct": 4, "Mostly correct": 3, "Somewhat correct": 2, and "Incorrect": 1 . The total score is 1500 . The group with the highest total score was the VR group with 1248 points. Then came the VRIT group with 1211 points, followed by the NVR group with 1153 points. The last group was the NVRIT group with 1094 points. Fig. 6 shows the total score and the number of times the highest score was obtained for each group. The scores for each question are shown in Table 2, with the highest score for each group shown in bold. 


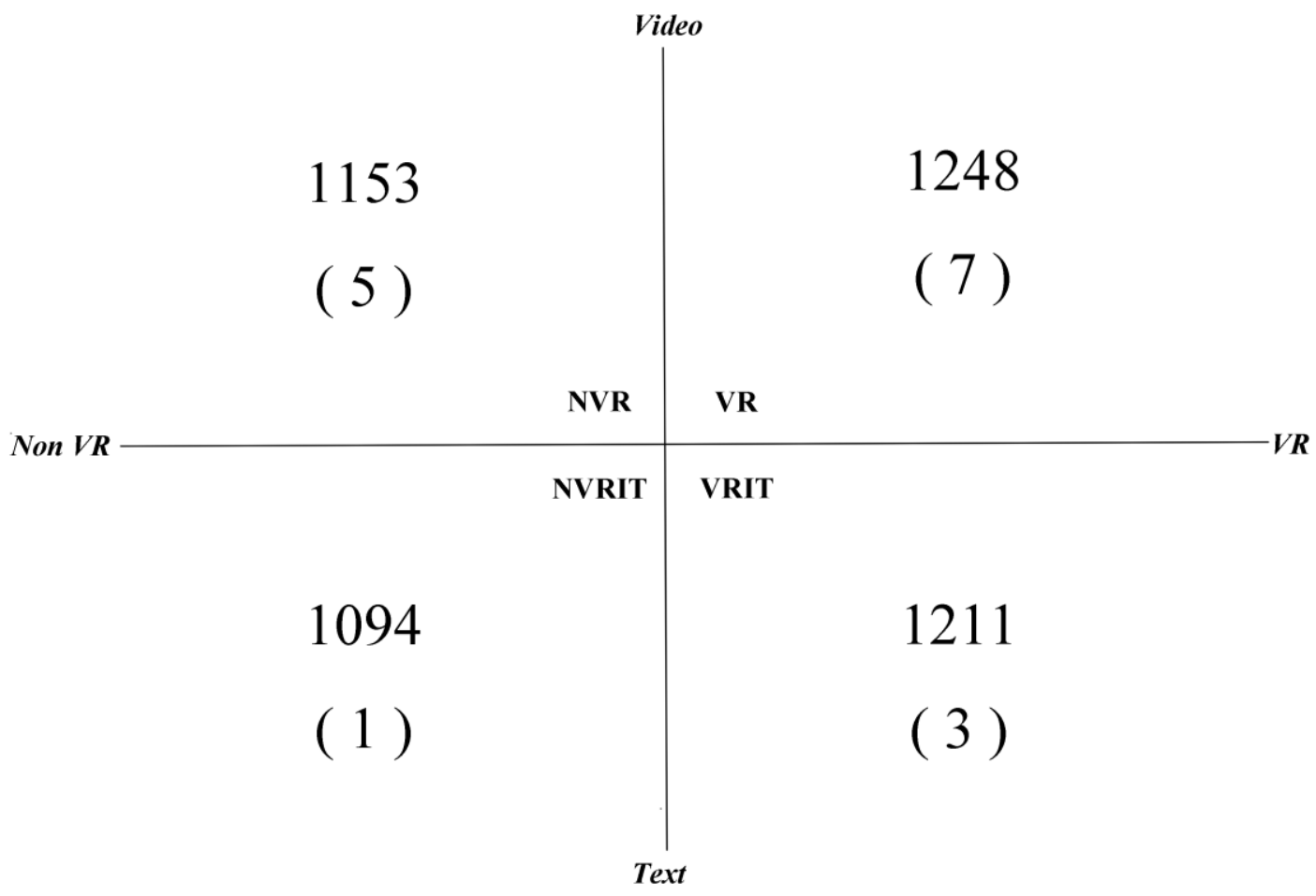

Figure 6. Spam traffic sample

Table 2. Score for each question

\begin{tabular}{l|llll} 
& NVRIT & NVR & VRIT & VR \\
\hline $\mathbf{1}$ & 124 & 127 & 124 & $\mathbf{1 3 8}$ \\
$\mathbf{2}$ & 113 & $\mathbf{1 2 0}$ & $\mathbf{1 2 0}$ & $\mathbf{1 2 0}$ \\
$\mathbf{3}$ & 112 & 129 & 136 & $\mathbf{1 4 1}$ \\
$\mathbf{4}$ & $\mathbf{1 2 0}$ & $\mathbf{1 2 0}$ & $\mathbf{1 2 0}$ & $\mathbf{1 2 0}$ \\
$\mathbf{5}$ & 93 & $\mathbf{1 0 2}$ & 98 & 99 \\
$\mathbf{6}$ & 100 & 112 & 119 & $\mathbf{1 3 7}$ \\
$\mathbf{7}$ & 105 & $\mathbf{1 1 0}$ & $\mathbf{1 1 0}$ & 94 \\
$\mathbf{8}$ & 107 & $\mathbf{1 3 5}$ & 117 & 114 \\
$\mathbf{9}$ & 126 & 102 & 131 & $\mathbf{1 4 6}$ \\
$\mathbf{1 0}$ & 94 & 114 & 136 & $\mathbf{1 3 9}$ \\
TOTAL & 1094 & 1153 & 1211 & $\mathbf{1 2 4 8}$ \\
SCORE & & & &
\end{tabular}

The results also show the following:

For the same data from a non-VR sample, a sample that presents the story through video can make subjects remember the information more accurately than a sample that presents the story through text.

For the same VR sample data, the visual storytelling sample helps subjects remember the information more accurately than the textual storytelling sample. 
Signal \& Image Processing: An International Journal (SIPIJ) Vol.12, No.5, October 2021

In the same sample data where the story was presented in text, the VR sample allows subjects to remember the information more accurately.

In the same sample data where the story was presented in video, the VR sample was able to make the participants remember the information more accurately.

The self-reports of the four groups found from the recognition survey are, in order from highest to lowest, "NVRIT> NVR> VRIT> VR". The total result was the exact opposite of the high-low ranking of the correct survey results.

These data validated the prediction that the means of getting subjects to remember the most information among the four groups was the VR news game with a story. When the sample presents the story in text, the VR sample gets subjects to remember the information, and the correct response rate is higher when the story is presented in video than when the sample presents it in text. For those who do not have a VR device, the higher correct response rate of the NVR group indicates that storytelling and gaming also prove that they can reinforce memory.

The NVR group had more questions that received the highest score than the VRIT group. This may mean that, depending on the type of question, "presenting the story in a video" was more effective than in getting the subjects to remember the information correctly.

So, to further analyze the data, the research divided the questions into three types.

I. Questions with a single answer. This is the simplest type of question, requiring only one answer from the subject. Questions 1, 2 and 4 belong to this type.

II. Questions that require multiple answers. This question is similar to the Type 1 question, but the experimenter needs to give more than one answer. Questions 3, 5 and 9 belong to this type.

III. Subjective questions. No clear answer is given in the sample, and the experimenter is required to organize the information by himself/herself and combine it with thinking to come up with an answer. Questions 6, 7, 8 and 10 belong to this type.

The scores are shown in Fig. 7. The first and second types of questions contain three questions, but the third group contains four questions, so the score for the third type of question can only be compared with its internal group. 
Signal \& Image Processing: An International Journal (SIPIJ) Vol.12, No.5, October 2021
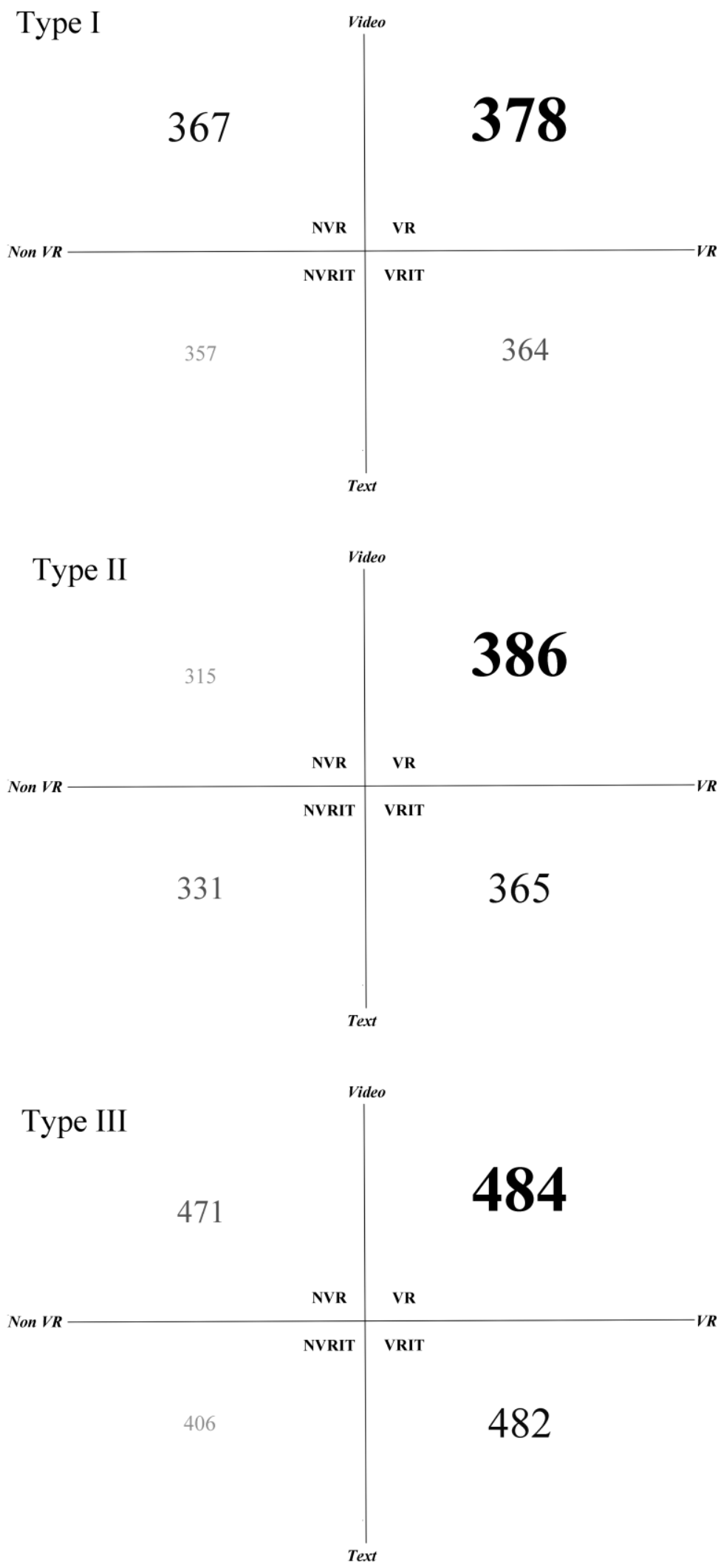

Figure 7. Scores for each type of question 
Signal \& Image Processing: An International Journal (SIPIJ) Vol.12, No.5, October 2021

For questions with a single answer, the scoring order and total score results for each group differed, with the VR group scoring the highest, while the NVR group came in second, ahead of the VRIT group. the NVRIT and NVR groups scored higher than for Type 2 questions, while the VRIT group's score was essentially the same. The VRIT group's score is basically the same. This result confirms what has been speculated so far: when there is only one answer, presenting the story in a video is slightly more effective in getting the subject to remember the information correctly. Based on the above results, if someone want to convey a single piece of information accurately but cannot meet the requirements of VR, "present the story in text" is the best choice.

Questions that require multiple answers also differ from the total score ranking. The score ranking for this type is VR>VRIT $>$ NVRIT $>$ NVR for non-VR, presenting the story in text is clearly better at getting the subject to remember the information accurately than presenting the story in video. Based on the above results, "presenting the story with text" is more effective than "presenting the story with video" in a non-VR environment for accurately conveying multiple pieces of information.

Question 9, why does the local government not want the public to know about the protagonist? The VR group had a very high percentage of correct answers, with 23 people answering "more than correct" and the remaining 7 also answering correctly. The VR group had more "more than correct" answers, so the criterion for "more than correct" for this question was to give three reasons for the question answer. The VR group had the highest number of "correct" responses. The VR group averaged 83 characters for this question, while the NVR group averaged only 15 characters. This suggests that the immersive nature of VR made the subjects more emotionally involved, promoted emotional empathy, and strengthened their memory [20].

There is also a high rate of questions and errors that are not fully connected to the story. For example, question 5, three suicide methods to ask the main character. Subjects have difficulty remembering all of them, and in most cases only remember two of the means. This is because these means did not cross over much with the subsequent story, especially when compared to question 4, the number of times the main character committed suicide. The subjects remembered the "suicide" episodes in the story well. The memory of "means" that are not related to the plot is much weaker.

The rankings of the subjective question scores and total scores are consistent: the difference between the VRIT and VR groups is small, and the difference between the NVRIT and NVR groups is the largest among the three types. Thus, in the subjective question, if the sample is in VR format, there is little difference in the amount of information correctly remembered between "presenting the story in text" and "presenting the story in video". However, when the sample is in a non-VR format, there is a large difference in the amount of information correctly remembered between "presenting the story with text" and "presenting the story with video".

In order to get a high score on a subjective question, more test takers need to be able to relate to it. From the data, the NVRIT group clearly has a larger gap in scores than the other three groups, and the difference value is the largest among the three types of questions.

\subsection{Empathy check}

As shown in Fig. 8, overall, the four groups tend to have basically high starts and low goals. The four levels of empathy are scored on a scale of 1 to 4 , from low to high. 


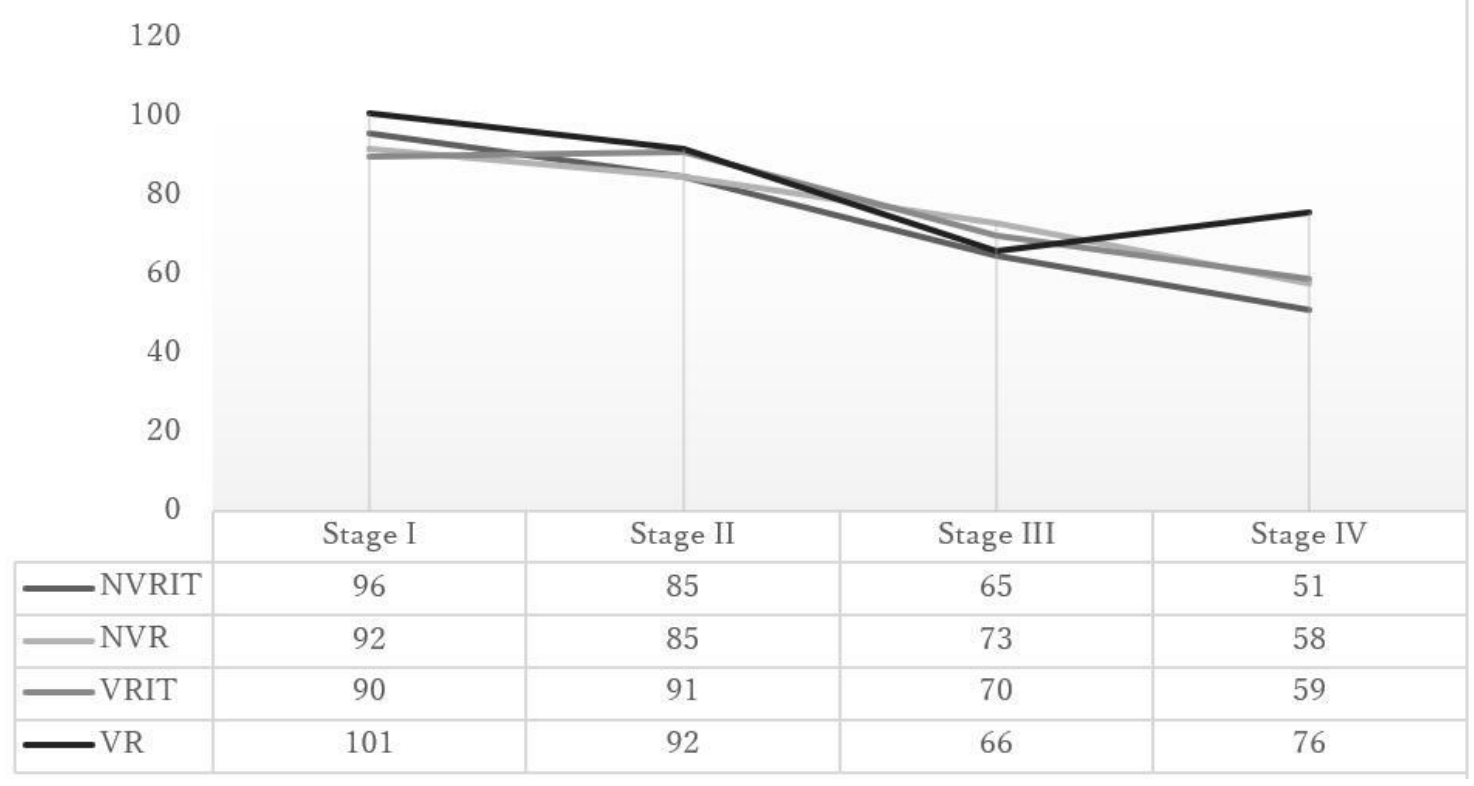

Figure 8. Empathy for each stage

The empathy for Stage 1 was the greatest not only because the first stage was the most novel, one study found that information is more memorable when it appears early in the story [21]. In order from highest to lowest, VR $>$ NVRIT $>$ NVR $>$ VRIT.

In Stage 2, the VRIT group has slightly higher empathy, basically the same as the data in Stage 1. In the other groups, empathy is less. However, they are still at the top of the list in the overall data. In order from highest to lowest values, VR $>$ VRIT $>$ NVR=NVRIT.

In Stage 3, empathy for all groups drops significantly. In particular, the VR group not only has the largest drop, but also has lower data than the NVR and VRIT groups. From highest to lowest values, NVR $>$ VRIT $>$ VR $>$ NVRIT. Stage 3 is the least difficult of all the stages, and also the least fearful. This stage has a simple color scheme, with simple scenes and color schemes, mainly white and gray, no background music, relatively slow enemy movement, and an important turning point where the protagonist's attitude toward life becomes more positive. The research speculated that this relationship may have caused a significant drop in empathy in the VR group. The researchers asked the NVR group again. The six subjects who chose Level 4 said that they were alarmed because they thought there was likely to be JUMP SCARE in a quiet environment. These six subjects were not fully immersed in the sample, but were more dependent on the game experience to feel tense. This may reflect the lower level of immersion of the NVR group.

In Stage 4, the empathy of the three groups except the VR group continued to decline, but more slowly than the decline in Stage 3. The empathy of the tension in the VR group increased. The order of values from highest to lowest is VR $>$ VRIT $>$ NVR $>$ NVRIT.

\subsection{Recording}

The recording is divided into two parts: the reproduction part and the impression part. Overall, there was little difference in the results between the four groups, basically focusing on fluency levels, with everyone being able to tell a rough story. A small number of subjects skipped certain episodes in the story, but quickly added more. From the results of this research, it appears that all four groups of subjects did well. 
Signal \& Image Processing: An International Journal (SIPIJ) Vol.12, No.5, October 2021

The key words that were mentioned more often in the feedback section are as follows:

" Kidnapping, hope, fear, creepy, background music, sound, children, Stockholm syndrome, angry, uncomfortable, heavy, shock, anxious, helpless, scene, suspicious."

Negative emotional keywords such as "scary" appeared more frequently. In order to increase the accuracy of the research, the research consciously set the game in a horror mood because several studies have shown that horror is helpful for memory [22].

\section{Conclusions ANd Future Development}

- In descending order of self-report of the four groups in the recognition check: NVRIT $>$ NVR $>$ VRIT $>$ VR.

- Exactly the opposite in the correctness check: VR $>$ VRIT $>$ NVR $>$ NVRIT.

- The ranking for the empathy check is the same as for the correctness survey: VR $>$ VRIT $>$ NVR $>$ NVRIT.

The recording is divided into the story retelling part, and all groups can finish telling the story smoothly. The keyword "scary" appears frequently in the impression section. The characteristics of the experimental results for each group can be summarized as follows:

- NVRIT: Among the four groups, the difference in performance between confidence in memory and the information actually remembered is the largest, and the number of "Get it" choices is the largest, which is different from the choice patterns of the other three groups. For questions that require multiple answers, the percentage of correct answers is higher than the NVR group. Empathy can be more successfully elicited by the subjects' experience of playing the game and reading the text. However, as the game progresses, they fall to the bottom of the four groups.

- NVR: The pattern of confidence in memory is similar to the other three groups, except for NVRIT, which ranks first among them. They rank second in the number of times they receive the highest score on the correctness check, and their performance on the singleanswer questions. The downward trend in empathy is relatively modest.

- VRIT: Test takers' confidence in their memory is slightly better than in the VR group. The difference in scores between the VRIT group and the VR group on the subjective questions of the correctness check is small for this group. The drop in empathy is the most moderate.

- VR: Of the four groups, the confidence in one's memory is the lowest. In the correctness check, they always rank first, regardless of the type of question. In the empathy check, they are consistently ranked first except for Stage 3. According to the post-experiment interview, the drop to third place is thought to be due to the drop in fear in Stage 3.

Of the four groups, the one that was able to remember the most information was the narrative VR news game. Subjects in this group also tended to be less confident in their own memories. Experiment shows a positive correlation between subjects' experience and their self-reported level of confidence in their memory. Similarly, experience in playing games and reading short texts may be the reason for the lack of confidence in one's memory. Studies have shown that audio enhances memory coding in virtual environments. This is another reason why the VR group always has a higher percentage of correct answers than the other three groups [23]. Nontext samples may yield more multimodal sensory information. However, some studies have shown that reading is also an interactive process [24], and in the case of the group of subjects in the current experiment, they have extensive reading experience. Therefore, the NVRIT group scored higher than the NVR group on the Type 2 question. 
Signal \& Image Processing: An International Journal (SIPIJ) Vol.12, No.5, October 2021

Further experiments will be conducted to see if this lack of confidence affects the profile of memory after an extended period of time.

When the sample is presented with a story in text, the VR sample is more likely to remember the information, and the sample presenting the story in video is more likely to answer correctly than the sample presenting the story in text. A number of studies have confirmed that empathy plays a role in the construction of our memories [25], [26]. This, coupled with the fact that it is an experimental result, further proves that the degree of empathy is positively correlated with the correctness of the memory.

Some argue that virtual reality is not ideal for increasing empathy [27] and that the effect of fear on memory cannot be ignored [28]. Taken together with the results of the current experiment, this suggests that immersion in virtual reality does not directly increase empathy, but that immersion can increase the fear of the sample and make them more empathetic in a narrative context. And empathy reinforces the memory that the subject was in the sample.

Studies have shown that people with higher empathy tend to take more helping actions [29]. In other words, the "narrative VR news game" not only helps the recipients to remember the news information better, but also increases their empathy, which makes them more interested in the news.

\section{ACKNOWLEDGEMENTS}

The authors would like to thank everyone, just everyone!

\section{REFERENCES}

[1] Ryan Bradley, How Nonny de la Peña, the 'Godmother of VR,' Is Changing the Mediascape, 2018

[2] Bryan Bishop , Digital empathy: how 'Hunger in Los Angeles' broke my heart in a virtual world, 2013

[3] Daniel J. Levitin, The Organized Mind: Thinking Straight in the Age of Information Overload, Pages 4,(2015)

[3] Masaaki Tanaka, Akira Ishii, Yasuyoshi Watanabe, Neural effects of mental fatigue caused by continuous attention load: A magneto encephalography study, Brain Research, Volume 1561, Pages 60-66, (2014)

[4] K.J. Anderson, Internet use among college students: an exploratory study, Journal of American College Health, volume 50, number 1, p Pages 21-26. (2001)

[5] Yu-Mei Wang and Marge Artero, Caught in the Web: University student use of Web resources, Educational Media International, volume 42, number 1, Pages. 71-82. (2005)

[6] Emily Moyer-Gusé, Howard Giles, Daniel Linz. Encyclopedia of Violence, Peace, \& Conflict (Second Edition). Pages 368-379. (2008)

[7] Christopher Pieper, Leonard D. Eron, L. Rowell Huesmann. Television Programming and Violence, US. Pages 2069-2078. (2008)

[8] Richard Philpot Lasse Liebst Mark Levine Wim Bernasco Marie Lindegaard, Would I be Helped? Cross-National CCTV Footage Shows That Intervention Is the Norm in Public Conflicts. Pages 3. (2019)

[9] Darley, J.M.; Latané, B. Bystander intervention in emergencies: diffusion of responsibility. Journal of Personality and Social Psychology. 8 (4): 377-383. (1968)

[10] Barron, G; Yechiam, E, Private E-mail requests and the diffusion of responsibility. Computers in Human Behavior. 18 (5): 507-520. (2002)

[11] Darley, J.M.; Latané, B. Bystander intervention in emergencies: diffusion of responsibility. Journal of Personality and Social Psychology. 8 (4): 377-383.1968 
Signal \& Image Processing: An International Journal (SIPIJ) Vol.12, No.5, October 2021

[12] Michael Smith." From Theory To Common Practice: Consumer Neuroscience Goes Mainstream”.(2016)https:/www.nielsen.com/us/en/insights/article/2016/from-theory-to-commonpractice-consumer-neuroscience/

[13] Tom Trabasso, Paul van den Broek, Causal thinking and the representation of narrative events, Journal of Memory and Language, Volume 24, Issue 5,1985,Pages 612-630,ISSN 0749-596X

[14] Harman, J., Brown, R., \& Johnson, D. (2017). Improved memory elicitation in virtual reality: New experimental results and insights. In R. Bernhaupt, G. D. Anirudha, J. Devanuj, K. Balkrishan, J. O’Neill, \& M. Winckler (Eds.), IFIP Conference on Human-Computer Interaction (pp. 128-146)

[15] Ruddle, R. A., Volkova, E., Mohler, B., \& Bülthoff, H. H. (2011). The effect of landmark and bodybased sensory information on route knowledge. Memory \& Cognition, 39(4), 686-699

[16] J. Clement, Virtual reality (VR) and augmented reality (AR) device ownership and purchase intent among consumers in the United States as of 1st quarter 2017, by gender.(2021)

[17] J. Clement, Distribution of video gamers in the United States from 2006 to 2020, by gender. Unpublished,(2021)

[18] Xiaohan Feng, Narrative theory in virtual reality Comparison of VR news game and non-VR news game. (2021)

[19] Cichoń, E., Gawęda, Ł., Moritz, S. et al. Experience-based knowledge increases confidence in discriminating our memories. Curr Psychol 40, 840-852. https://doi.org/10.1007/s12144-018-0011-8, 2021

[20] Buckner, R. L., \& Carroll, D. C. Self-projection and the brain. Trends in Cognitive Sciences, 11(2), 49-57. https://doi.org/10.1016/j.tics.2006.11.004.(2007)

[21] Abigail C. Doolen \& Gabriel A. Radvansky (2021) A novel study: long-lasting event memory, Memory

[22] Ginting, Henndy. It is Fear, Not Disgust, That Enhances Memory: Experimental Research on Students in Bandung. anima. 31. 77-83. (2016)

[23] Andreano, J., Liang, K., Kong, L., Hubbard, D., Wiederhold, B. K., \& Wiederhold, M. D. (2009). Auditory cues increase the hippocampal response to unimodal virtual reality. Cyberpsychology \& Behavior, 12(3), 309-313

[24] Alan M. Lesgold \& Charles A. Perfetti (1978) Interactive processes in reading comprehension, Discourse Processes, 1:4, 323-336, DOI: 10.1080/01638537809544443

[25] Spreng, R. N., \& Grady, C. L. Patterns of Brain Activity Supporting Autobiographical Memory, Prospection, and Theory of Mind, and Their Relationship to the Default Mode Network. Journal of Cognitive Neuroscience, 22(6), 1112-1123. https://doi.org/10.1162/jocn.2009.21282, (2009)

[26] Spreng, R. N., Mar, A. R., \& Kim, A. S. N. The Common Neural Basis of Autobiographical Memory, Prospection, Navigation, Theory of Mind, and the Default Mode: A Quantitative Meta-analysis. Journal of Cognitive Neuroscience, 21(3), 489-510. https://doi.org/10.1162/jocn.2008.21029, (2009)

[27] Rueda, Jon \& Lara, Francisco, Virtual Reality and Empathy Enhancement: Ethical Aspects. Frontiers in Robotics and AI. 7. 10.3389/frobt.2020.506984. (2020)

[28] Ginting, Henndy. It is Fear, Not Disgust, That Enhances Memory: Experimental Research on Students in Bandung. anima. 31. 77-83. (2016)

[29] Liao, Wan-Ting \& Tzeng, Angela. The-Mechanism-Underlying-Empathy-Related-Helping-BehaviorAn-Investigation-of-Empathy-Attitude--Action-Model. (2020) 